\title{
The Impact of Self Blood Glucose Monitoring and Insulin Regimen on Glycemic Control among Children and Adolescents with Type 1 Diabetes Mellitus
}

\author{
Abdulmoein E Al-Agha ${ }^{1,2 *}$, Shireen A Samargandy', Ihab Abd elhameed Ahmed ${ }^{3}$ and Douaa Ahmed El Derwi \\ ${ }^{1}$ Faculty of Medicine, King Abdulaziz University, Jeddah, Saudi Arabia \\ ${ }^{2}$ Department of Pediatrics, Faculty of Medicine, King Abdulaziz University, Jeddah, Saudi Arabia \\ ${ }^{3}$ Department of Pediatrics (Ahmad), Faculty of Medicine, Zagazig University, Zagazig, Egypt \\ ${ }^{4}$ Faculty of Dentistry, King Abdulaziz University, Jeddah, Saudi Arabia
}

\begin{abstract}
Background: Type 1 diabetes (T1DM) is a chronic metabolic disorder. Factors affecting glycemic control including insulin regimen and glucose monitoring are important aspects in management of this disease.

Objective: We aimed to investigate the relationship between glycemic control measured as glycosylated hemoglobin (HbA1c) with self-monitoring of blood glucose (SMBG) and insulin regimen in children and adolescents with T1DM.

Methods: A cross-sectional questionnaire-based study looking into SMBG and insulin regimens among children and adolescents diagnosed with T1DM in King Abdulaziz University Hospital.

Results: The study population was composed of $(n=230)$ patients. The mean level of $\mathrm{HbA} 1 \mathrm{c}$ was $8.79 \pm 2.58 \%$. The majority of patients $(98.6 \%)$ were on intensive insulin therapy. Most frequently used $(84.5 \%)$ type of insulin regimen was the intermediate plus short acting insulin. Statistical analysis revealed no significant association between various factors such as gender, age, type of insulin, SMBG, nor glucose correction with glycemic control.

Conclusion: SMBG and intensive insulin therapy were suggested in literature as predictors of well-controlled T1DM. However, in our Saudi population, the results were not statistically significant enough to make such an association. Nevertheless, it is good practice to emphasize the value of SMBG and regular insulin injections in improving diabetic care.
\end{abstract}

Keywords: Diabetes mellitus; Glycosylated hemoglobin; Insulin; Blood glucose; Monitoring

\section{Introduction}

Diabetes mellitus is a common metabolic disorder that is chronically progressive if not properly managed. The demanding nature of this disease mandates a high level of awareness and sense of responsibility from the patients towards their ailment, in addition to rigorous followup with their health care providers.

The current recommendations are in support of achieving tight glycemic control in order to decrease the morbidity and premature mortality related to microvascular and macrovascular disease $[1,2]$. With the trend of insulin treatment being shifted towards intensive therapy, the balance between achieving adequate control and lesser complications, mainly hypoglycemia, is problematic [1]. Hence, monitoring of blood glucose became of increasing value. Literature review reveals associations between blood glucose monitoring and glycemic control [3-8]. Insulin regimens have been suggested to have an effect on blood glucose control as well [1,9-11]. To the extent of our knowledge, no local study in Saudi Arabia addressing this matter was done on a pediatric population diagnosed with type $1 \mathrm{DM}$ (T1DM).

This study was conducted with the aim of uncovering the interrelationships between blood glucose monitoring and the satisfactoriness of glycemic control. In addition, we analyzed the effects of different insulin regimens on the glycemic control.

\section{Material and Methods}

\section{Study design and data collection methods}

A cross-sectional questionnaire-based study design was used. A set of standardized data collection sheets entailing a series of questions with multiple answer choices was utilized. The study population was formed of children and adolescents diagnosed with T1DM recruited from patients seeking specialty diabetic care in the pediatric endocrinology outpatient clinics at King Abdulaziz University Hospital (KAUH), a tertiary health care center in Jeddah, Saudi Arabia. Patients with a minimum duration of illness of 12 months were included in this study. None of them were in the honeymoon period. This was confirmed by c-peptide levels that fell within the normal range according to our lab measurements $(0.16-1.68 \mathrm{nmol} / \mathrm{L})$ in all of the patients. Patients with major data insufficiency due to incomplete questionnaires were excluded. Approval from the KAUH's ethical committee was obtained.

Each patient was assessed at one point in time in a single clinic visit. The questionnaires were collected over the course of one year from (January, 2013) until (January, 2014). The care providers or the patients themselves filled them in. Patients have given their verbal consent for participation in this study. The inquiries made pertained to

*Corresponding author: Dr. Abdulmoein E. Al-Agha, FRCPCH, Assistant Professor and Consultant Pediatric Endocrinologist, Department of Pediatrics, King Abdulaziz University Hospital, P.O. Box 80215, Jeddah 21589, Kingdom of Saudi Arabia, Tel: 00966-2-6408327; Fax: 00966-2-6408353; E-mail: aagha@kau.edu.sa

Received March 12, 2015; Accepted May 11, 2015; Published May 14, 2015

Citation: Al-Agha AE, Samargandy SA, Abd elhameed Ahmed I, Derwi DAE (2015) The Impact of Self Blood Glucose Monitoring and Insulin Regimen on Glycemic Control among Children and Adolescents with Type 1 Diabetes Mellitus. J Diabetes Metab 6: 548. doi:10.4172/2155-6156.1000548

Copyright: (c) 2015 Al-Agha AE, et al. This is an open-access article distributed under the terms of the Creative Commons Attribution License, which permits unrestricted use, distribution, and reproduction in any medium, provided the original author and source are credited. 
Citation: Al-Agha AE, Samargandy SA, Abd elhameed Ahmed I, Derwi DAE (2015) The Impact of Self Blood Glucose Monitoring and Insulin Regimen on Glycemic Control among Children and Adolescents with Type 1 Diabetes Mellitus. J Diabetes Metab 6: 548. doi:10.4172/21556156.1000548

overall diabetic health of the patients. For the purpose of this research, the segments involving socio demographics, home glucose monitoring, insulin therapy and metabolic control will be focused on.

$\mathrm{HbA1c}$ is a frequently used measure of glycemic control. The goal for glycemic control is usually set at less than $7.5 \%$ for all age groups, but the goal is individualized [12]. The mean of HbAlc readings over the preceding year was used for each individual patient. At $\mathrm{KAUH}$, $\mathrm{HbA} 1 \mathrm{c}$ is measured using the SEIMENS Dimension clinical chemistry system using a GLU Flex reagent cartridge. Hexokinase method is the laboratory test utilized.

\section{Definitions}

The participants were divided into four age groups, which were less than 5 years, between 5 and 10 years, between 10 and 15 years, and more than 15 years. In our region, we observed an earlier age of puberty, hence we have defined the pre-pubertal age group as; being less than 10 years old, and pubertal; more than 10 years old. Patients were also divided into three categories according $\mathrm{HbA1c}$ levels; good glycemic control with $\mathrm{HbA1c}<7 \%$, moderate with $\mathrm{HbA} 1 \mathrm{c} 7-9 \%$, and poor control with $\mathrm{HbAlc}>9 \%$. Patients were receiving one of two insulin regimens; conventional or intensive. Conventional insulin regimen was defined as the administration of 2 injections of insulin per day as a combination of short-acting and intermediate-acting insulin prior to breakfast and dinner, coupled with blood glucose monitoring and flexible adjustments of insulin dosage in response to the individual's metabolic control by correction of hyperglycemia with short- or rapid-acting insulin. Intensive insulin regimen was defined as receiving 3 or more insulin injections per day or receiving a basalbolus regimen of insulin. Insulin basal-bolus regimen was defined as an insulin pump therapy, or rapid- or short-acting insulin injection before each meal in addition to a single long-acting dose to cover the basal need for insulin between meals and during the night. The patients visiting our clinic were educated by their diabetic care team (which includes a pediatric endocrinologist, diabetic educator, and dietician) to do four self-blood glucose tests every day, once before each meal as a minimum. Additional tests (more than four) would be done two hours post-prandial. In the event that the blood glucose was found to be higher than their age-specific targets, the caregivers of a young child or the adolescent patients themselves were taught to use either the insulin sliding scale or correction equation of blood glucose according to the educational level of the patient and family. The equation for correction utilizes age, weight and total daily dose as its variables.

\section{Statistical analysis}

The data were compiled from the collected questionnaires. Data entry and analysis was done using SPSS version 16.0 software. Continuous variables were represented as mean $( \pm \mathrm{SD})$ and categorical variables as percentages. When appropriate, Chi-square test and cross tabulations were applied for the analysis of categorical data. Missing data were excluded from the analysis. A p-value of $<0.05$ was determined to be statistically significant for individual variables.

\section{Results}

The total number of patients approached with the questionnaires was 480 patients. The number of participants who agreed to participate was $(n=230)$, with a response rate of $48 \%$. Mean age of participants was $11.24 \pm 4.3$ years. Mean $\mathrm{HbAlc}$ was $8.79 \pm 2.58 \%$. Nineteen percent $(n=43)$ of the participants had a HbAlc level less than $7 \%, 46.2 \%$ $(n=104)$ had HbAlc levels between 7 and 9\%, and 34.7\% $(n=78)$ had HbA1c levels above $9 \%$. Overall, $(n=143,62.2 \%)$ of the participants were females, $(n=87,37.8 \%)$ were males. The pre-pubertal and pubertal group accounted for $(n=95,41.9 \%)$ and $(n=132,58.1 \%)$ of the total respectively. Upon comparison of glycemic control groups according to pubertal age, statistical analysis revealed a p-value of 0.427 . Table 1 depicts the glycemic control according to gender and further age subgroupings. With regards to the insulin regimen used in our patients, the total numbers of patients on conventional therapy was $(n=3,1.4 \%)$, while the intensive insulin therapy group had a sum of 216 patients (98.6\%). Comparing the different glycemic control groups according to the intensity of the insulin therapy had a p-value of 0.47 . Five patients were on insulin pump therapy. Patients receiving intermediate and short acting insulin (NPH and Regular) were 180 patients of the total (84.5\%). Ones on basal insulin analog and rapid or short acting insulin were 31 patients (13.5\%). Only 3 patients were on premixed insulin (1.3\%). HbA1c levels are shown in Table 2 according to the type of insulin used as part of an intensive insulin regimen. SMBG was done in the majority of cases (98\%). Of the 226 patients with available data, $87(38.5 \%)$ patients had a SMBG frequency of once daily, $64(28.3 \%)$ patients of twice daily and $75(33.2 \%)$ patients of three or more times daily. The frequency and method of home glucose correction is represented in Table 3.

\section{Discussion}

HbA1c levels higher than the target level (7.5\%) was found in more than two thirds $(69.2 \%)$ of the patients. For this purpose, we divided glycemic control into three groups as mentioned in the material and methods section. The majority (46.2\%) of the patients had HbAlc levels between $7 \%$ and $9 \%$.

Most of the patients were female (62.7\%). Gender was not deemed a significant predicting factor for metabolic control of T1DM in our study population ( $p$-value $=0.165)$.

Levels of HbA1c appeared higher in children older than 5 years old with a p-value approaching significance of 0.076 . The highest percentage of well-controlled $\mathrm{HbA1c}$ level $(<7 \%)$ was found in children less than 5 years old, while the rest of the age groups had $\mathrm{HbA} 1 \mathrm{c}$ levels

\begin{tabular}{|c|c|c|c|c|c|}
\hline Variable & HbA1c $<7 \%$ & $\begin{array}{c}\text { HbA1c } \\
7-9 \%\end{array}$ & $\begin{array}{c}\text { HbA1c } \\
>9 \%\end{array}$ & Total & P-value \\
\hline Age groups & \multicolumn{4}{|c|}{ Number of patients $(\%)^{*}$} & \\
\hline$<5$ years & $8(40)$ & $6(30)$ & $6(30)$ & 20 & \multirow{5}{*}{0.076} \\
\hline $5-10$ years & $13(17.8)$ & $37(50.7)$ & $23(31.5)$ & 73 & \\
\hline $10-15$ years & $16(15.8)$ & $43(42.6)$ & $42(41.6)$ & 101 & \\
\hline$>15$ years & $5(17.9)$ & $17(60.7)$ & $6(21.4)$ & 28 & \\
\hline Total & 42 & 103 & 77 & 222 & \\
\hline \multicolumn{5}{|l|}{ Gender } & \\
\hline Male & $19(22.6)$ & $32(38.1)$ & $33(39.3)$ & 84 & \multirow{3}{*}{0.165} \\
\hline Female & $24(17)$ & $72(51.1)$ & $45(31.9)$ & 141 & \\
\hline Total & 43 & 104 & 78 & 225 & \\
\hline
\end{tabular}

* Values between brackets are relative frequencies (\%)

Table 1: Glycemic control according to age group and gender.

\begin{tabular}{|c|c|c|c|c|c|}
\hline \multirow[t]{2}{*}{ Type of insulin } & $\begin{array}{c}\text { HbA1c } \\
<7 \%\end{array}$ & $\begin{array}{c}\text { HbA1c } \\
7-9 \%\end{array}$ & $\begin{array}{c}\text { HbA1c } \\
>9 \%\end{array}$ & Total & \multirow[t]{2}{*}{ P-value } \\
\hline & \multicolumn{4}{|c|}{ Number of patients ${ }^{*}(\%)^{\star *}$} & \\
\hline Intermediate and short acting & $36(20)$ & $82(45.6)$ & $62(34.4)$ & 180 & \multirow{3}{*}{0.843} \\
\hline $\begin{array}{l}\text { Basal analog and Rapid/Short } \\
\text { acting }\end{array}$ & $5(16.1)$ & $14(45.2)$ & $12(38.7)$ & 31 & \\
\hline Total & 41 & 96 & 74 & 211 & \\
\hline
\end{tabular}

Table 2: Glycemic control according to type of insulin used. 
Citation: Al-Agha AE, Samargandy SA, Abd elhameed Ahmed I, Derwi DAE (2015) The Impact of Self Blood Glucose Monitoring and Insulin Regimen on Glycemic Control among Children and Adolescents with Type 1 Diabetes Mellitus. J Diabetes Metab 6: 548. doi:10.4172/21556156.1000548

Page 3 of 4

\begin{tabular}{|c|c|c|c|c|c|}
\hline Variable & $\begin{array}{c}\text { HbA1c } \\
<7 \%\end{array}$ & $\begin{array}{c}\text { HbA1c } \\
7-9 \%\end{array}$ & $\begin{array}{c}\text { HbA1c } \\
>9 \%\end{array}$ & Total & P-value \\
\hline $\begin{array}{l}\text { Home glucose } \\
\text { correction }\end{array}$ & \multicolumn{4}{|c|}{ Number of patients* $(\%)^{\star *}$} & \\
\hline Done & $34(17.7)$ & $90(46.9)$ & $68(35.4)$ & 192 & \multirow{3}{*}{0.599} \\
\hline Not done & $7(24.1)$ & $14(48.3)$ & $8(27.6)$ & 29 & \\
\hline Total & 41 & 104 & 76 & 221 & \\
\hline \multicolumn{6}{|c|}{$\begin{array}{l}\text { Method of glucose } \\
\text { correction }\end{array}$} \\
\hline Sliding scale & $27(17.8)$ & $69(45.4)$ & $56(36.8)$ & 152 & \multirow{3}{*}{0.761} \\
\hline Equation & $7(17.5)$ & $21(52.5)$ & $12(30)$ & 40 & \\
\hline Total & 34 & 90 & 68 & 192 & \\
\hline
\end{tabular}

Table 3: Glycemic control and home glucose correction.

more than $7 \%$ in over $82 \%$ of the cases. One possible explanation is that children in the pre-school age are supervised directly by their parents most of the time, however after they enter school many influencing factors arise; such as lack of supervision from busy teachers or easier access to high carbohydrate snacks from peers.

The poorest glycemic control (>9\%) was found in $41.6 \%$ of the 10 - to 15 years age group. Paradoxically, the pubertal age group -defined by the cut-off of 10 years old- did not influence glycemic control ( $p$-value $=0.427$ ). There are numerous bio psychosocial changes taking place during the pubertal age that may be contributing factors to a pediatric patient's glycemic control. It is well-established that hormones secreted at puberty are associated with insulin resistance which compromises glycemic control [13]. There is also an array of behavioral changes that may take place during this critical developmental period, further affecting metabolic control. They include increased psychological stress and anxiety, emotional lability, unpredictability in daily routines, neglecting proper diet and exercise, and inclination towards deleterious health behaviors such as smoking and eating disorders [13].

\section{Insulin therapy}

A review of literature is suggestive of a direct relationship between the insulin regimen type, number of daily insulin injections and mode of administration with adequacy of metabolic control in T1DM [1,911]. As very few (1.4\%) of our patients were on conventional therapy, the difference between the two regimens did not yield a statistically significant relationship ( $p$-value $=0.47)$. Most of the patients were on the intermediate plus short/rapid acting types of insulin (84.5\%). Whether the patient was using the aforementioned insulin types or the basal analog plus short/rapid acting insulin, no statistically significant difference was found upon comparing the glycemic control groups ( $p$-value $=0.843)$. None of the patients on premixed insulin achieved an adequate glycemic control, which could be due to the lack of flexibility of the pre-mixed regimen compared to the others.

\section{Blood glucose monitoring}

The relation between performing SMBG and glycemic control in diabetes is widely discussed in literature, with numerous studies reporting an inverse relationship between the frequency of SMBG per day and the levels of glycated hemoglobin $\mathrm{A} 1 \mathrm{C}(\mathrm{HbA1c})$ as the measure for glycemic control $[1,3-8,10]$. This result was not reproducible in our study. Participants' adherence to home blood glucose monitoring did not seem to have a notable impact on HbA1c (Spearman's correlation co-efficient $=0.026$, $p$-value $=0.711$ ). Most of the patients in our study were only performing SMBG once a day at home, which could be a contributing factor to the less than satisfactory glycemic control. The parents play a role in this matter as well. Decreased frequency of blood glucose monitoring in children with little parental involvement has been previously demonstrated in a study by Anderson et al. [6]. Action was taken to correct the blood glucose based on the glucometer readings in the majority of the study population $(n=192,86.8 \%)$. The sliding scale was the more prevalent method for correction $(n=152$, $79.2 \%)$. There was no change in glycemic control according to home glucose correction $(p$-value $=0.599)$ or its method $(p$-value $=0.761)$.

\section{Conclusion}

In conclusion, it is imperative for the treating physicians and diabetic counselors to collaborate with the patient in order to improve glycemic control, safe-keep the patients from possible complications, and ensure their overall well-being. Special attention must be directed towards the pubertal group to detect worsening of metabolic control. Emphasizing the importance of frequently performing SMBG amongst patients and option for intensive insulin therapy are both recommended $[14,15]$. Further studies must be performed looking at other factors that could alter the metabolic control amongst the pediatric Saudi population diagnosed with T1DM.

\section{Conflicts of Interest}

No financial support is to be reported. All authors report no conflicts of interest relevant to this article.

\section{References}

1. Diabetes Control and Complications Trial Research Group (1993) The effect of intensive treatment of diabetes on the development and progression of long-term complications in insulin-dependent diabetes mellitus. N Engl J Med; 329:977-986.

2. Ray KK, Seshasai SR, Wijesuriya S, Sivakumaran R, Nethercott S, et al. (2009) Effect of intensive control of glucose on cardiovascular outcomes and death in patients with diabetes mellitus: a meta-analysis of randomised controlled trials. Lancet; 373 (9677): 1765-1772.

3. Schramm W (2012) Self-monitoring of blood glucose: one STeP forward? J Diabetes Sci Technol; 6: 978-982.

4. Ziegler R, Heidtmann B, Hilgard D, Hofer S, Rosenbauer J, et al (2011) Frequency of SMBG correlates with $\mathrm{HbA} 1 \mathrm{c}$ and acute complications in children and adolescents with type 1 diabetes. Pediatr Diabetes; 12: 11-17.

5. Helgeson VS, Honcharuk E, Becker D, Escobar O, Siminerio L (2011) A focus on blood glucose monitoring: relation to glycemic control and determinants of frequency. Pediatr Diabetes; 12: 25-30.

6. Anderson B, Ho J, Brackett J, Finkelstein D, Laffel L (1997) Parenta involvement in diabetes management tasks: relationships to blood glucose monitoring adherence and metabolic control in young adolescents with insulindependent diabetes mellitus. J Pediatr; 130: 257-265.

7. Schütt M, Kern W, Krause U, Busch P, Dapp A, et al. (2006) DPV Initiative: Is the frequency of self-monitoring of blood glucose related to long-term metabolic control? Multicenter analysis including 24,500 patients from 191 centers in Germany and Austria. Exp Clin Endocrinol Diabetes; 114: 384-388.

8. Bergenstal RM, Ahmann AJ, Bailey T, Beck RW, Bissen J, et al. (2013) Recommendations for standardizing glucose reporting and analysis to optimize clinical decision making in diabetes: the Ambulatory Glucose Profile (AGP). Diabetes Technol Ther; 15: 198-211.

9. Paris CA, Imperatore G, Klingensmith G, Petitti D, Rodriguez B, et al. (2009) Predictors of insulin regimens and impact on outcomes in youth with type 1 diabetes: the SEARCH for Diabetes in Youth study. J Pediatr; 155: 183-189.

10. Svoren BM, Volkening LK, Butler DA, Moreland EC, Anderson BJ, et al. (2007) Temporal trends in the treatment of pediatric type 1 diabetes and impact on acute outcomes. J Pediatr; 150: 279-285.

11. Jakisch BI, Wagner VM, Heidtmann B, Lepler R, Holterhus PM, et al. (2008) German/Austrian DPV Initiative and Working Group for Paediatric Pump 
Citation: Al-Agha AE, Samargandy SA, Abd elhameed Ahmed I, Derwi DAE (2015) The Impact of Self Blood Glucose Monitoring and Insulin Regimen on Glycemic Control among Children and Adolescents with Type 1 Diabetes Mellitus. J Diabetes Metab 6: 548. doi:10.4172/21556156.1000548

Page 4 of 4

Therapy. Comparison of continuous subcutaneous insulin infusion (CSII) and multiple daily injections (MDI) in paediatric Type 1 diabetes: a multicentre matched-pair cohort analysis over 3 years. Diabet Med; 25: 80-85.

12. International Society for Pediatric and Adolescent Diabetes. ISPAD 2011.

13. Leonard Jack, Jr. (2003) Biopsychosocial factors affecting metabolic control among female adolescents with type 1 diabetes. Diabetes Spectrum;16: 3154 159

14. American Diabetes Association. Standards of Medical Care in Diabetes-2013. Diabetes Care; 2013; 36: S11-S66.

15. Daneman D (2006) Type 1 diabetes. Lancet; 11; 367: 847-858. 